\title{
Simulating the interaction of solitary wave and submerged horizontal plate using SPH method
}

\author{
Mirhossein Aghili, Parviz Ghadimi*, Yaser Faghfoor Maghrebi, Hashem Nowruzi \\ Amirkabir University of Technology \\ *Corresponding author E-mail:pghadimi@aut.ac.ir
}

Copyright $\odot 2014$ Aghili et al. This is an open access article distributed under the Creative Commons Attribution License, which permits unrestricted use, distribution, and reproduction in any medium, provided the original work is properly cited.

\begin{abstract}
In the current study, weekly compressible smooth particle hydrodynamics (WCSPH) method is implemented to simulate solitary wave interaction with horizontal submerged plate at four different vertical positions. To accomplish this task, MLS density filter is applied to reduce the pressure fluctuations. Moreover, Symplectic scheme with dynamic boundary particle (DBP) is considered. Free surface profile, pressure, and vertical component of the wave force on the horizontal plate parameters are computed in this study. The obtained numerical results of solitary wave and its interaction with a horizontal plate are compared against existing experimental data and very good compliance is achieved. CFD results indicate that as distance of the horizontal plate from free surface decreases, wave energy reduces significantly. On the other hand, with an increase in horizontal plate distance from the seabed, vertical component of wave force and its pressure component substantially decrease.
\end{abstract}

Keywords: WCSHP; submerged horizontal plate; pressure; wave force; solitary wave.

\section{Introduction}

Shorelines are considered as potentials of commercial activities and tourism. There are several ways of protecting these coastal areas such as using breakwaters and quays. Floating and semi-submerged breakwater is considered as an alternative choice than conventional submerged breakwater and quays, since conventional breakwaters are complicated in construction and because of sediment aggregations in their offshore surroundings. In addition, their geometrical specifications will cause environmental incompatibility [1]. On the other hand, some comparative advantages of semi submerged horizontal floating breakwater plates against submerged breakwaters include their placement in only one part of the water depth and preserving the costal landscape.

Several experimental studies dealing with the investigation of wave interaction with marine structures have been reported. Mikio [2] used Marker and Cell method to simulate the characteristics of submerged floating plate. Ohyama et al. [3], by using wave height gauges, measured the water level while stokes waves passing over submerged floating breakwater. Pinto [4] measured velocity components during wave breaking over submerged breakwaters in short time intervals. Particle image velocity method (PID) was used by Chang et al. [5] to measure the flow field over submerged floating rectangular breakwater and field rotation as well as turbulence energy were calculated. Orer et al. [6] investigated the capability of submerged breakwater as an energy converter through an experimental study on the efficiency of the submerged plate wave energy converter. Akinori et al. [7] studied the currents and waves around a trapezoidal breakwater experimentally and theoretically. Hong Bin et al. [8] investigated deformation of different wave profiles over trapezoidal submerged breakwaters and seawalls, experimentally. Wan et al. [9] experimentally and theoretically conducted the interaction of solitary wave and a multi body breakwater with two cylindrical parts.

Several numerical studies dealing with investigation of wave interaction with marine structures using smoothed particle hydrodynamic have been reported. Monaghan et al. [10] applied SPH method to model the phenomena of interaction of a rigid body with water and compared the outputs with experimental results. Shao [11] modeled the effects of solitary wave on a semi-submerged membrane breakwater using ISPH. Different wave amplitudes of solitary waves in a variable depth were used for this simulation. Gomez et al. [12] studied the effects of solitary waves caused by dam break on a structure using SPH. They also used SPH method for analyzing wave propagation resulting from dam break 
on a structure. Rogers et al. [13] conducted a numerical study to investigate the movement of a Kayson breakwater under the effects of wave force in a wave breaking zone by using SPH. They also modeled friction force changing from static to dynamic between Keyson breakwater and seabed. Lee et al. [14] investigated the run up of waves on sea shore structures by SPH. A comprehensive SPH computer program was also developed by Crespo [15] to solve 2D and 3D fluid dynamic problems. Liu et al. [16] developed an optimized SPH method for modeling of 3D waves. On the other hand, Hayatdavoodi et al. [17] investigated nonlinear solitary wave propagation on a submerged flat plate using G-N equations to estimate the pressure distribution on the plate and determined the vertical force due to wave. Ghadimi et al. [19] numerically simulated the solitary wave propagation by using SPH and studied the effects of wave height to wave depth ratio, parametrically. Safinaz [20] simulated solitary waves using SPH and studied the hydrodynamic forces on slope and vertical parts. Monaghan et al. [21] numerically modeled solitary waves by using SPH and compared the run up and breaking waves with experimental results. Loa et al. [22] simulated solitary waves near the slopes at low depth shores by using combined SPH and LES method by solving incompressible Lagrangian Navier Stokes equation. They also modeled solitary waves on different slopes at low depth shores. Darlymple et al. [23] simulated the solitary wave using different algorithms and filters such as density filter and viscosity filter.

Based on the mentioned studies, geotechnical and hydraulic characteristics of floating breakwaters such as vertical location of breakwaters have a major role on their behavior. Hence, to achieve an appropriate operational depth of floating horizontal plate, numerical parametric studies are conducted using SPH method in the current work. For this purpose, four different vertical locations of a horizontal plate from seabed to free surface are applied in a constant sea depth. Accordingly, free surface profile, pressure, and vertical component of the wave force on the horizontal plate parameters are computed. Numerical findings are also compared against existing experimental data.

\section{Fundamentals of SPH}

Navier Stokes equation is the main governing equation in fluid dynamics that could be divided in two parts [24].Momentum conservation equation in a continuous field can be expressed as follows:

$$
\frac{D \vec{v}}{D t}=-\frac{1}{\rho} \vec{\nabla} P+\vec{g}+\vec{\Theta}
$$

Continuity equation could be expressed as follows:

$$
\frac{1}{\rho} \frac{D \rho}{D t}+\nabla \vec{v}=0
$$

Where, $\mathrm{v}$ is velocity, $\mathrm{P}$ is pressure, $\rho$ is density, $\mathrm{g}$ is gravity acceleration and $\Theta$ is the diffusion term. Governing equations can be discredited and solved using main concepts of SPH method. Application of the SPH method leads to determination of velocity, position and pressure of fluid particles in the next step. Fundamentals of this method are based on solving the mass conservation equation by assuming that the fluid semi-compressible.

\subsection{Integral Interpolation}

SPH method is based on integral interpolation for any arbitrary function like A(r) which can be approximated as follows:

$$
A(r)=\int_{\Omega} A\left(r^{\prime}\right) W\left(r-r^{\prime}, h\right) d r
$$

Here, $\mathrm{r}$ is the position vector; $\mathrm{W}$ is a weighting function or kernel function and according to Fig. 1 , $\mathrm{h}$ is the smoothing length that controls the support domain of $\Omega$. 


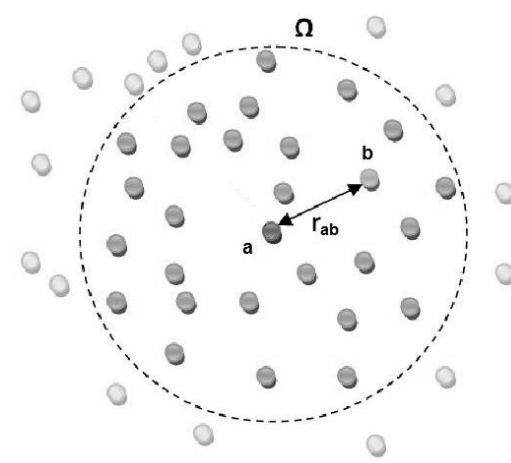

Fig. 1: A Schematic of support domain in SPH.

Approximation shown in discrete form in Eq.3, leads to the following approximation of a function for a particle:

$$
A(r)=\sum_{b} m_{b} \frac{A_{b}}{\rho_{b}} W_{a b}
$$

In this equation, $A_{b}$ is the value of function A at position of the particle b. Mass and density are shown by $m_{b}, \rho_{b}$. Parameter $W_{a b}=W\left(r_{a}-r_{b}, h\right) \partial$ represents the kernel function. Finally, using the approximation of the particle $\mathrm{b}$ inside the support domain, Eq.5 appears as in:

$\nabla A(r)=\sum_{b} m_{b} \frac{A_{b}}{\rho_{b}} \nabla W_{a b}$

Several models of kernel approximation have been presented [25, 26, 27], but one of the most common functions in SPH is Cubic Spline that is given by Monaghan et al. [28]. This function is also used in the current article. The kernel function for Cubic Spline is presented in the following form:

$W(r, h)=\alpha_{D}\left\{\begin{array}{lr}\frac{3}{4} q^{3}-\frac{3}{2} q^{2}+1 & 0 \leq q \leq 1 \\ \frac{1}{4}(2-q)^{3} & 1 \leq q \leq 2 \\ 0 & q \geq 2\end{array}\right.$

Where $\alpha_{D}$ is equal to $10 /\left(7 \pi h^{2}\right)$ in $2 \mathrm{D}$ solutions and $1 /\left(\pi h^{3}\right)$ in 3D solutions.

\subsection{Viscosity selection}

There are various definitions for transmission term to explain momentum equation in SPH [27, 29], but laminar viscous stress is used in this article [30]. Momentum conservation equation with laminar viscous stress is expressed as follows:

$$
\frac{D \vec{v}}{D t}=-\frac{1}{\rho} \vec{\nabla} P+\vec{g}+v_{0} \nabla^{2} \vec{v}
$$

Viscous stress is simplified as follows [30]:

$$
\left(v_{0} \nabla^{2} \vec{v}\right)_{a}=\sum_{b} m_{b}\left(\frac{4 v_{0} \vec{r}_{a b} \vec{\nabla}_{a} W_{a b}}{\left(\rho_{a}+\rho_{b}\right)\left|\vec{r}_{a b}\right|^{2}}\right) \vec{v}_{a b}
$$


Where $v_{0}$ shows kinematic viscosity for laminar flows, and for water, it is $\left(10^{-6} \mathrm{~m}^{2} / \mathrm{s}\right)$. Thus, the governing equations can be rewritten as in:

$$
\begin{aligned}
& \frac{D \vec{v}_{a}}{D t}=-\sum_{b} m_{b}\left(\frac{P_{a}}{\rho_{a}^{2}}+\frac{P_{b}}{\rho_{b}^{2}}\right) \vec{\nabla}_{a} W_{a b}+\vec{g}+\sum_{b} m_{b}\left(\frac{4 v_{0} \vec{r}_{a b} \vec{\nabla}_{a} W_{a b}}{\left(\rho_{a}+\rho_{b}\right)\left|\vec{r}_{a b}\right|^{2}}\right) \vec{v}_{a b} \\
& \frac{D \rho_{a}}{D t}=\sum_{b} m_{b} \vec{v}_{a b} \vec{\nabla}_{a} W_{a b}
\end{aligned}
$$

\subsection{Selecting the time step algorithm}

There are many ways of solving SPH equations in time domain, but it is recommended to use a method with second order precision [31, 32]. For this reason, Symplectic method is applied in the present article. According to this algorithm [33], pressure and density are calculated in the middle of the time step by using formulas:

$$
\begin{aligned}
& \rho_{i}^{n+1 / 2}=\rho_{i}^{n}+\frac{\Delta t}{2} \frac{d \rho_{i}^{n}}{d t} \\
& r_{i}^{n+1 / 2}=r_{i}^{n}+\frac{\Delta t}{2} \frac{d r_{i}^{n}}{d t}
\end{aligned}
$$

Where $\mathrm{t}$ is equal to $\mathrm{n} . \Delta \mathrm{t}$. Later, pressure is calculated using state equation. Subsequently, using $\frac{d\left(\omega_{i} \rho_{i} v_{i}\right)^{n+1 / 2}}{d t}$ gives the velocity and particle displacement.

$$
\begin{aligned}
& \left(\omega_{i} \rho_{i} v_{i}\right)^{n+1}=\left(\omega_{i} \rho_{i} v_{i}\right)^{n+1 / 2}+\frac{\Delta t}{2} \frac{d\left(\omega_{i} \rho_{i} v_{i}\right)^{n+1 / 2}}{d t} \\
& r_{i}^{n+1}=r_{i}^{n+1 / 2}+\frac{\Delta t}{2} v_{i}^{n+1}
\end{aligned}
$$

At the end of a time step, the value of $\frac{d \rho_{i}^{n+1}}{d t}$ is calculated by updated values of $\frac{d \rho_{i}^{n+1}}{d t}$ and $r_{i}^{n+1}$. Another time algorithm that is related to particle movement is XSPH that is derived by the following function [3].

$$
\frac{D \vec{r}_{a}}{D t}=\vec{v}_{a}+\varepsilon \sum_{b} \frac{m_{b}}{\bar{\rho}_{a b}} \vec{v}_{b a} W_{a b}
$$

In which $\bar{\rho}_{a b}=\frac{1}{2}\left(\rho_{a}+\rho_{b}\right)$ and $\varepsilon$ is a constant. The value of $\varepsilon$ is between 0 and 1 , and ordinarily $\varepsilon=0.5$ is used. New velocity for particle " $a$ " is a combination of the velocity of particle $a$ and the average velocity of particles that has interactions with particle $a$.

\section{Numerical model}

Aim of the current article is to simulate waves passing over a semi submerged horizontal plate at different vertical positions. First, a solitary wave is generated by a piston wave maker. This wave passes over a semi submerged plate. Here, the wave maker equations are mentioned, briefly. Goring [38] proposed a mathematical model for an experimental solitary wave. The surface profile of the solitary wave is presented as follows:

$$
\eta(x, t)=H \operatorname{sech}^{2}(k(x-C t))
$$

Where $\mathrm{C}$ is the wave velocity and $\mathrm{k}$ is the wave factor that can be calculated as follows: 


$$
\begin{aligned}
k & =\sqrt{\frac{3 H}{4 h^{3}}} \\
C & =\sqrt{g(h+H)}
\end{aligned}
$$

The piston wave maker (in SPH) consists of moving particles that is used to generate wave patterns with specific velocity and positions. To create a solitary wave by a piston wave maker, the following formulas are applied:

$$
\begin{aligned}
& X_{o}(t)=\frac{H}{k}\left[\tanh (X(t))+\tanh \left(\frac{k}{h} \lambda\right)\right] \\
& X(\mathrm{t})=\frac{k}{h}\left(C t-X_{o}(t)-\lambda\right)
\end{aligned}
$$

Movement velocity of the wave maker is calculated by the following equation [52]:

$$
u_{o}(t)=\frac{C H}{h} \cdot \frac{1}{\cosh ^{2} X(t)+\frac{H}{h}}
$$

In this article, effect of solitary wave on different vertical position of the plate is investigated. Figure 2 shows the position of these plates and the geometry of the intended simulation.

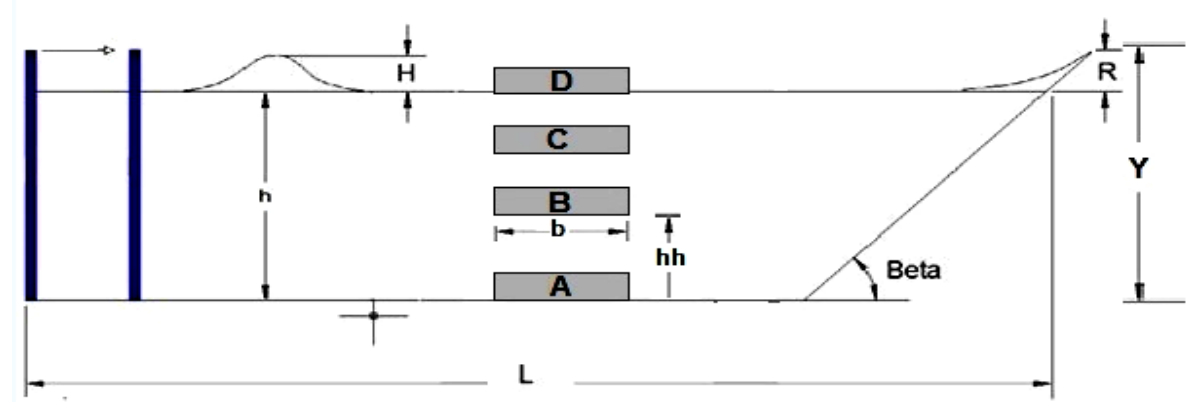

Fig. 2: A Schematic of different vertical positions of a submerged horizontal plate.

Next, solitary wave and passing of waves over a submerged horizontal plate as a validation case for numerical results is presented.

\section{Numerical results}

\subsection{Validation}

\begin{tabular}{|c|c|c|}
\hline \multirow{7}{*}{ Test Geometry } & Basin length & $30 \mathrm{~m}$ \\
\hline & Y(Basin height) & $0.35 \mathrm{~m}$ \\
\hline & Depth $(\mathrm{h})$ & $0.2 \mathrm{~m}$ \\
\hline & $\mathrm{H} / \mathrm{h}$ & 0.12 \\
\hline & Width of plate (b) & $4 \mathrm{~m}$ \\
\hline & Wave height $(\mathrm{H})$ & $0.024 \mathrm{~m}$ \\
\hline & $(\lambda)$ & $4.1867 \mathrm{~m}$ \\
\hline \multirow{4}{*}{$\begin{array}{c}\text { Position of the Horizontal } \\
\text { Plate }\end{array}$} & Case A & $\mathrm{h}=0$ \\
\hline & Case B & $\mathrm{h}=0.5 \mathrm{~h}$ \\
\hline & Case $\mathrm{C}$ & $\mathrm{h}=0.75 \mathrm{~h}$ \\
\hline & Case D & $\mathrm{h}=\mathrm{h}$ \\
\hline
\end{tabular}

In this section, simulation results are compared with Sangita experimental data [39] to validate the generated wave. Also, the computed run up waves on a submerged horizontal plate is also compared with Ertkin's experimental results [17]. Flume Geometry and considered cases are shown in Table 1.

Table 1: Flume Geometry and considered cases. 
45000 particles are used in this simulation. Comparison of the results of simulation of solitary wave by SPH method against the Sangita experimental data is shown in Fig.3.

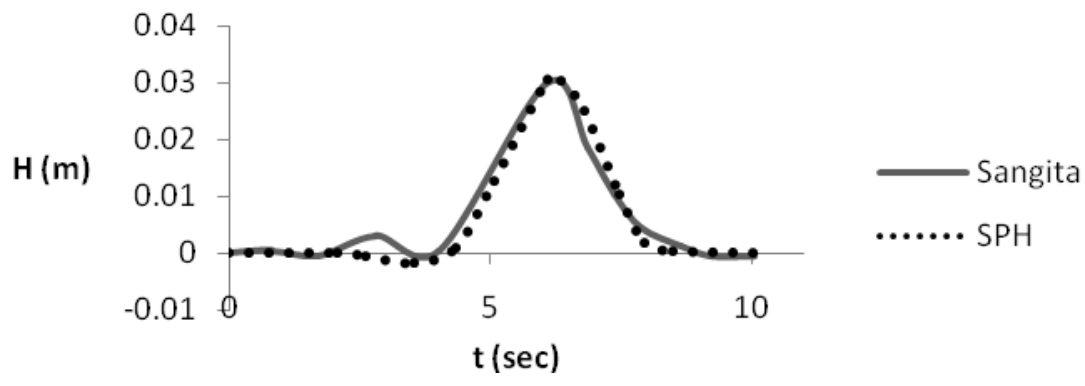

Fig. 3: Comparison of solitary wave results by SPH with Sangita experimental data [39].

As seen in Fig.3, the results have an acceptable correspondence and the average error is about $4.1 \%$. Thus, validity of solitary waves generated by piston wave maker has been confirmed. Verification of run up waves on a submerged horizontal plate is also checked with Ertkin's experimental data [17]. The geometry of this experiment is shown in Fig.4. Total number of particles in this simulation is about 360000 particles.

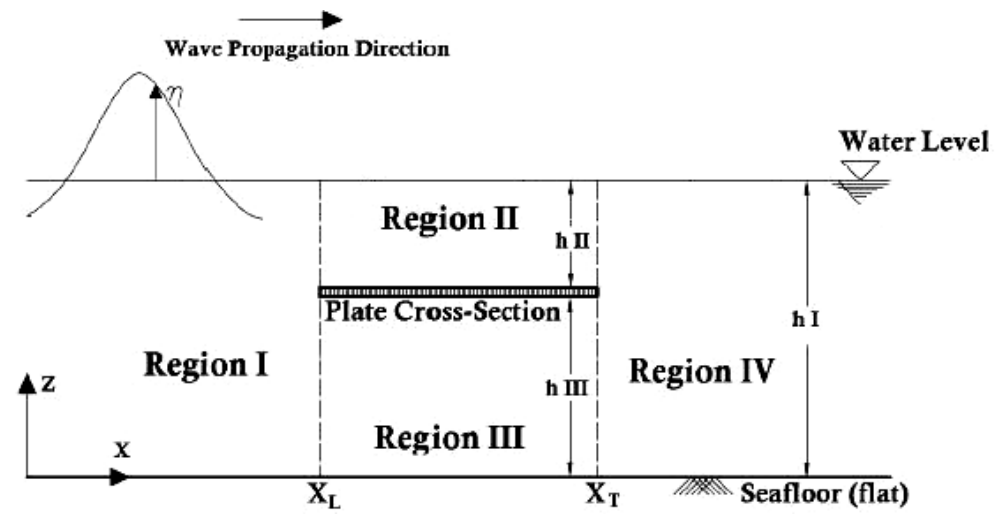

Fig. 4: A simple sketch of wave over the submerged horizontal plate [17].

Figure 5 shows the locations of wave gauges I, II, and III. These gauges indicate the wave parameters such as wave height and wave period.

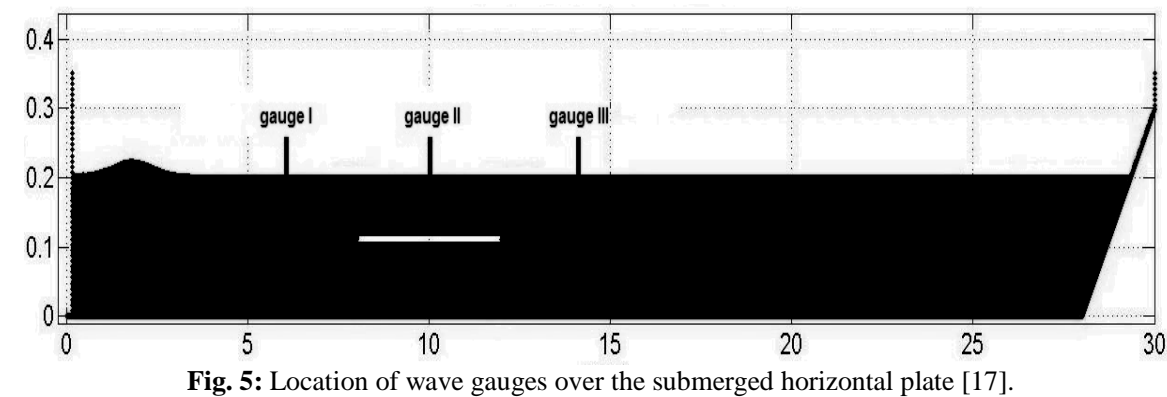

Free surface profile is captured at three different locations; before the plate (gauge I), on the plate (gauge II), and after the plate (gauge III). The obtained results were compared with Ertkin's experimental result [17] in Fig.6. 

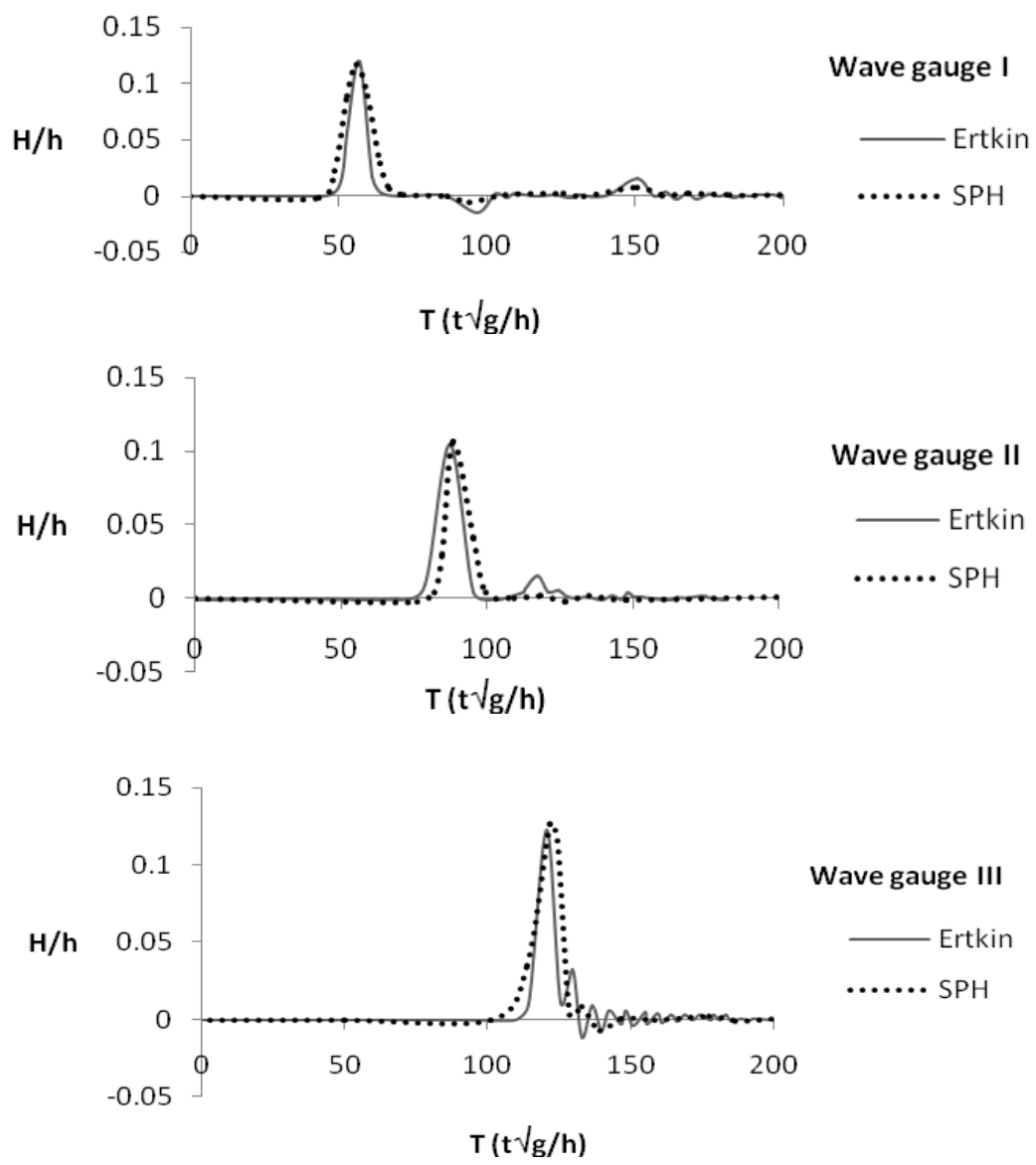

Fig. 6: Wave Surface profile at three different positions; wave gauge $\mathrm{I}$ at $\mathrm{x}=6 \mathrm{~m}$, wave gauge $\mathrm{II}$ at $\mathrm{x}=10 \mathrm{~m}$, and wave gauge III at $\mathrm{x}=14 \mathrm{~m}$ [17].

Computational error is calculated at three positions. The error for these conditions is about $3.8 \%$ before the plate (gauge I), $6.1 \%$ on the plate (gauge II) and $6.64 \%$ after the plate (gauge III). These errors seem reasonable for the presented numerical simulation.

Subsequently, measurement accuracy for pressure and force of the wave passing a semi-submerged horizontal plate is discussed using Ertkin experimental work. Calculation of the pressure using SPH initially had significant computational errors. To overcome this problem, several strategies are used. The density filter is used to solve this problem and additionally number of particles is increased to minimize the computational error.

Figure 7 shows a comparison of the calculated pressure by SPH with Ertkin's experimental results [17].

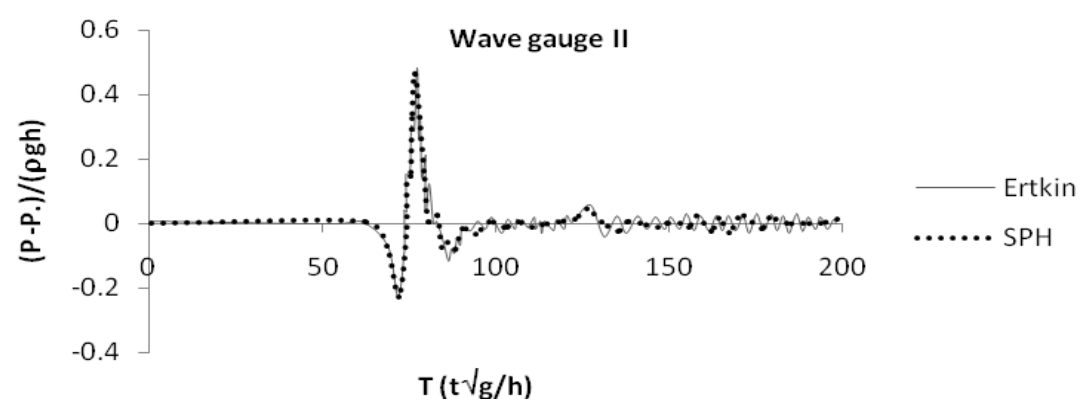

Fig. 7: Comparison of the calculated pressure by SPH method with Ertkin at $\mathrm{x}=10 \mathrm{~m}$ [17].

As expected, just before wave reaches the plate, we have a sudden loss of pressure and then the pressure is increases. These results have acceptable error of about 4.9 percents with Ertkin.

Vertical force is also obtained by integrating the pressure results along the plate's width at each time step. Figure 8 shows the comparison of SPH results with Ertkin's experimental results [17]. 


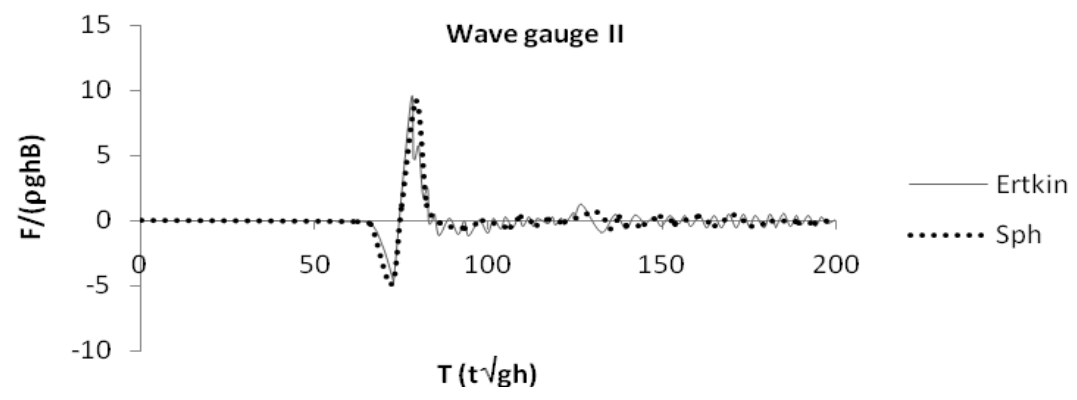

Fig. 8: Comparison of the calculated force on submerged plate using SPH with Ertkin's experimental data [17].

As expected, the results have an acceptable convergence and the average error is about $4.2 \%$.

\section{Parametric study on vertical position of submerged plate under the effects of solitary wave}

Here, the effects of interaction of the wave and the position of submerged horizontal plate on pressure and vertical force are investigated. The considered geometry for this problem is similar to Fig. 4 and Table 1 with one exception that position of the plate has changed. Figures 9 through 11 illustrate the surface profile for each case that is compared with previous simulation where the plate located is in the middle of actual depth. Figures 12 and 13 show the results of pressure and vertical force in these cases.

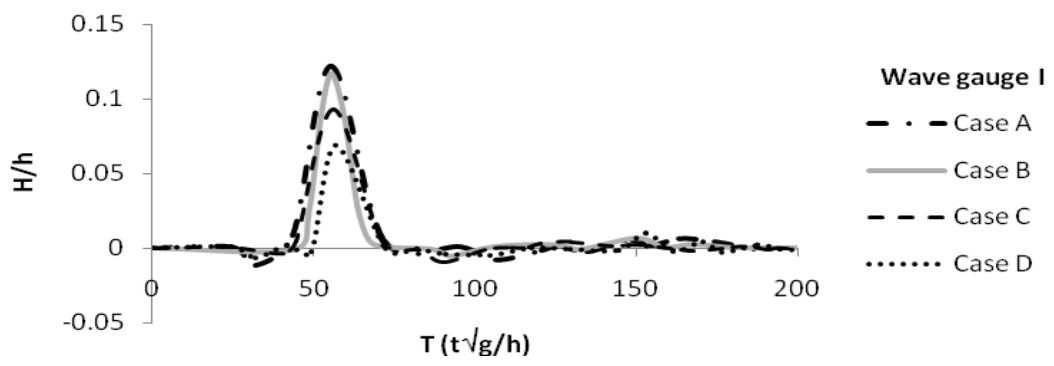

Fig. 9: Free surface profile at the position of wave gauge I.

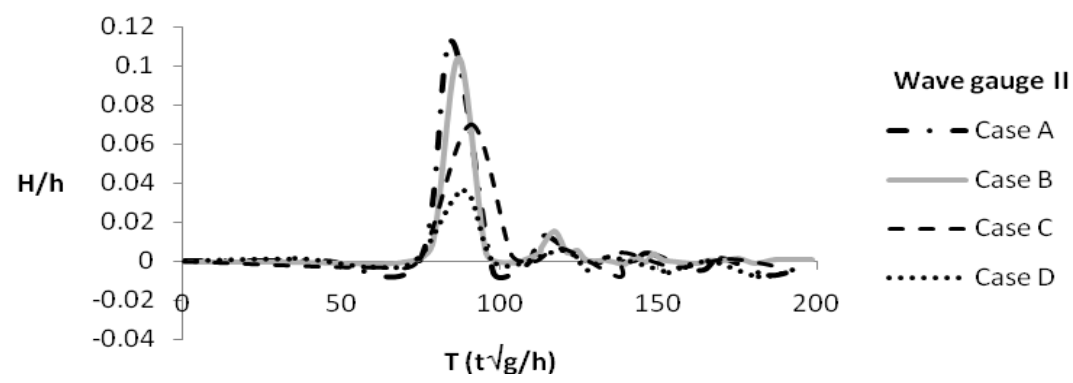

Fig. 10: Free surface profile at the position of wave gauge II

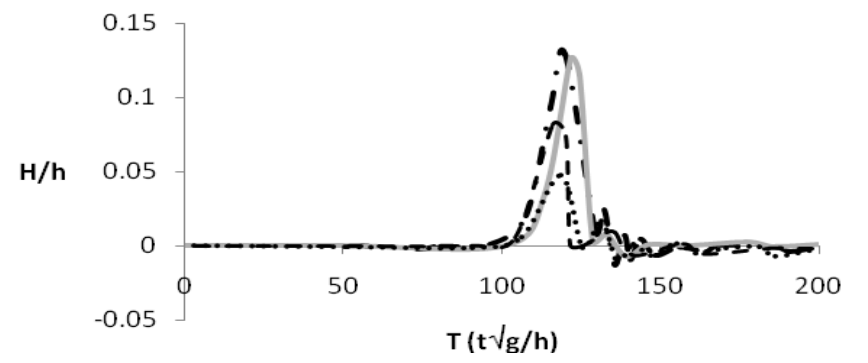

Wave gauge III

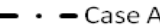

Case B

- - Case C

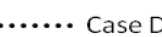

Fig. 11: Free surface profile at the position of wave gauge III. 
As evidenced in Figs.9, 10, and 11, wave surface elevation decreases by changing the vertical position of horizontal plate toward the surface.

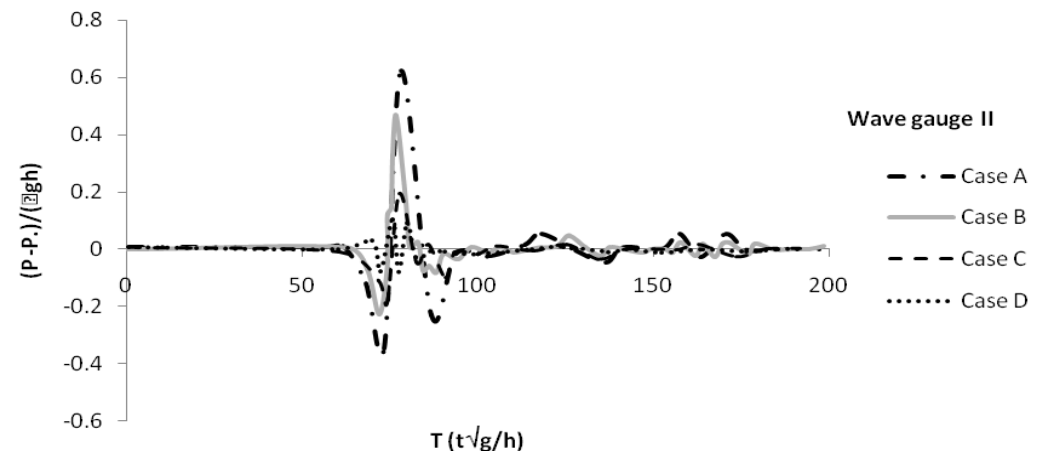

Fig. 12: Comparison of the calculated pressure by SPH method at wave gauge II location.

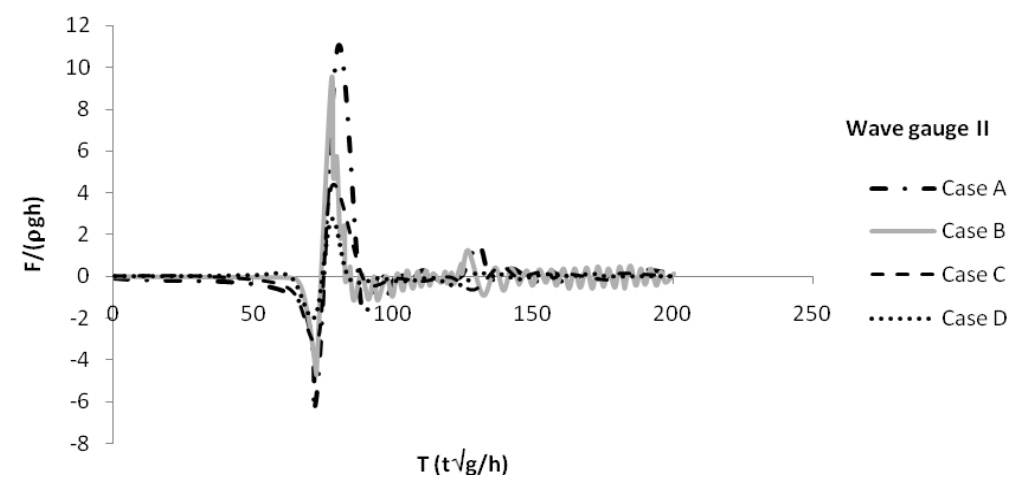

Fig. 13: Comparison of the calculated vertical force by SPH method.

Comparison of the results is shown in tables 2, 3, 4, and 5. Tables 2 and 3 show the maximum values of $\mathrm{H} / \mathrm{h}$, while tables 4 and 5 indicate the maximum values of pressure and vertical component of wave force.

Table 2: Maximum values of $\mathrm{H} / \mathrm{h}$ at different gauge positions.

\begin{tabular}{|c|c|c|c|}
\multicolumn{1}{c|}{ Table 2: Maximum values of H/h at different gauge positions. } \\
\cline { 2 - 4 } \multicolumn{1}{c|}{} & Gauge I & Gauge II & Gauge III \\
\hline Position A & 0.121918 & 0.11255 & 0.128982 \\
\hline Position B & 0.119252 & 0,10668 & 0.126492 \\
\hline Position C & 0.119252 & 0,069908 & 0.081659 \\
\hline Position D & 0.093151 & 0.036283 & 0.047236 \\
\hline
\end{tabular}

Table 3: Comparison of maximum values of $\mathrm{H} / \mathrm{h}$ at different depths.

\begin{tabular}{|c|c|c|c|}
\cline { 2 - 4 } \multicolumn{1}{c|}{} & Gauge I & Gauge II & Gauge III \\
\hline From position A to B & 0.002666 & 0.00587 & 0.00249 \\
\hline From position B to C & 0.026101 & 0.036772 & 0.044833 \\
\hline From position C to D & 0.024384 & 0.033625 & 0.034423 \\
\hline
\end{tabular}

Table 4: Percentage of surface profile change due to the plate's position.

\begin{tabular}{|l|l|l|l|}
\cline { 2 - 4 } \multicolumn{1}{c|}{} & Gauge I & Gauge II & Gauge III \\
\hline From position A to B & $43 \%$ & $67 \%$ & $63 \%$ \\
\hline From position B to C & $41 \%$ & $65 \%$ & $62 \%$ \\
\hline From position C to D & $4 \%$ & $5 \%$ & $2 \%$ \\
\hline
\end{tabular}

Tables 2, 3, and 4 show that, as the position of horizontal plate changes gets closer to D or farther away from the seabed, the wave height significantly reduces. 
Table 5: Maximum non-dimensional pressure and force.

\begin{tabular}{|c|c|c|}
\cline { 2 - 3 } \multicolumn{1}{c|}{} & Non dimensional Pressure & Non dimensional Force \\
\hline Position A & 0.623325 & 11.058 \\
\hline Position B & 0.465116 & 9.28571 \\
\hline Position C & 0.194906 & 4.33973 \\
\hline Position D & 0.054074 & 2.72005 \\
\hline
\end{tabular}

Table 6: Maximum non-dimensional pressure and force by changing vertical positions.

\begin{tabular}{|l|c|c|}
\cline { 2 - 3 } \multicolumn{1}{c|}{} & Non dimensional Pressure & Non dimensional Force \\
\hline From position A to B & 0.158209 & 1.77229 \\
\hline From position B to C & 0.27021 & 4.94598 \\
\hline From position C to D & 0.140832 & 1.61968 \\
\hline
\end{tabular}

Table 7: Percentage of pressure and force change due to the plate's position.

\begin{tabular}{|c|c|c|}
\cline { 2 - 3 } \multicolumn{1}{c|}{} & Pressure & Force \\
\hline From position A to B & $91 \%$ & $75 \%$ \\
\hline From position B to C & $88 \%$ & $71 \%$ \\
\hline From position C to D & $25 \%$ & $16 \%$ \\
\hline
\end{tabular}

As evidenced in Tables 5, 6, and 7, as the position of the horizontal plate gets closer to the free surface level or farther away from the seabed; the pressure and force on the breakwater substantially reduce.

\section{Conclusions}

In this paper, computational fluid dynamic simulation of solitary wave interaction with a floating, semi-submerged and submerged horizontal plate has been performed. This is accomplished at a constant water depth with four different vertical positions of horizontal plate from seabed to free surface. Smooth Particle Hydrodynamic (SPH) method is used to conduct these simulations. In doing so, Symplectic scheme with dynamic boundary particle (DBP) is considered and MLS density filter is applied to reduce pressure fluctuations.

Passing wave profile has been determined at three different gauges, and pressure and vertical component of wave force on the horizontal plate are computed. The obtained results of solitary wave simulation are validated against experimental results and good agreement is achieved. Moreover, under defined simulation conditions, passing wave profile, pressure and vertical component of wave force on a submerged horizontal plate is validated against experimental data.

Based on the numerical results, it can be concluded that, as vertical position of the horizontal plate gets closer to free surface, further wave energy depreciation is achieved. In addition, by comparison of maximum values of $(\mathrm{H} / \mathrm{h})$ at different vertical positions of the submerged plates, it can be concluded that as the plate moves near the free surface, wave height decreases, significantly. Furthermore, numerical results of pressure and vertical components of wave force at different vertical positions of the horizontal plate indicate that a decrease in the distance of plate from the seabed yields in major increase in the pressure and wave force component.

\section{References}

[1] Yu, X.; "Functional performance of a submerged and essentially horizontal plate for offshore wave control: a review", Coastal Eng. J, 2002, p.p. $127-147$

[2] Mikio, T.; "Hydrodynamic forces on a submerged plate", Proceedings of the Eleventh International Offshore and Polar Engineering Conferece Stavanger, Norway, 2001,p.p. 17-22

[3] Ohyama, T.; Kioka, W.; Tada, A.; “Applicability of numrtical models to nonlinear dispersive waves”, J.Coastal Eng, 1995,p.p. 297-313

[4] Pinto, F.; "Regular water wave measurements near submerged breakwaters", Mwas. Sci. Technol, 2005, p.p. 1883-1888

[5] Chang, K. A.; Hsu, T. J.; Liu P. L. F.; "Vortex generation and evolution in water waves propagating over a submerged rectangular obstacle, Part I. Solitary wave", Coastal Engineering, 2001, p.p. 13-36

[6] Orer, G.; Ozdamar, A.; "An experimental study on the efficiency of the submerged plate wave energy converter", Renewable Energy, 2006, p.p. $1317-1327$

[7] Akinori, Y.; Shuguang Y.; Masaru, Y.; and Isao I.;" Wave field behind a double-submerged breakwater", International Offshore and Polar Engineering Conference,2002

[8] Hong Bin, Ch.; Ching Piao, T.; and Chun Chieh, J.;" Wave transformation between submerged breakwater and seawall”, Journal of Coastal Research,2007

[9] Wan, D.; Wu, G.;" Numerical simulation of solitary wave interaction with submerged multi bodies”, journal of mechanical press, 1998 
[10] Monaghan, J.J.; Kos, A.; Issa, N.; "Fluid motion generated by impact", Journal of the Waterway Port, Coastal and Ocean Division, Vol. 129, 2003, p.p. 250-259,

[11] Shao, S.; "SPH simulation of solitary wave interaction with a curtain-type breakwater", Journal of Hydraulic Research, Vol. 43, 2005, p.p. 366-375

[12] Gómez, M.; Dalrymple, R.A.; "Using a 3D SPH method for wave impact on a tall structure”, Journal of the Waterway Port, Coastal and Ocean Division, Vol. 130, 2004, p.p. 63-69

[13] Rogers, B.; Dalrymple, R.; Stansby, P.; "Simulation of caisson breakwater movement using 2-D SPH”, Journal of Hydraulic Research, Vol. 48, 2010, p.p. 135-141

[14] Lee, E.S.; Violeau, D.; Benoit, M.; Issa, R.; Laurence, D.; and Stansby, P.; "Prediction of wave overtopping on coastal structures by using extended Boussinesq and SPH models", Proc. 30th International Conference on Coastal Engineering, 2006, p.p.4727-4740

[15] Crespo, A.; "Application of the smoothed particle hydrodynamics model SPHysics to free surface hydrodynamics", Ph.D. thesis, University of De Vigo, 2008

[16] Liu, Ch.; Zhang, J.; Sun, Y.;" The optimization of sph method and its application in simulation of water wave", Seventh International Conference on Natural Computation, 2011

[17] Hayatdavoodi, M.; Ertekin, R.C.; "Nonlinear forces on a Submerged, Horizontal Plate: The G-N Theory”, Proc. of the 27th Int. Workshop on Water Waves and Floating Bodies, Copenhagen, 2012, p.p. 22-25,

[18] Green, A.E.; Naghdi, P.M.; "Directed fluid sheets in Proceedings of the Royal Society of London", Mathematical and Physical Sciences, Vol. 347, 1976, p.p. $447-473$

[19] Ghadimi, P.; Abtahi, Sh.; Dashtimanesh, A.; "Numerical Simulation of Solitary Waves by SPH Method and Parametric Studies on the Effect of Wave Height to Water Depth Ratio", International Journal of Engineering and Technology, 2012, p.p. 453-465

[20] Safinaz, El,; " SPH modeling of solitary waves and resulting hydrodynamic forces on vertical and sloping walls", Department of Civil Engineering University of Ottawa, October. 2012

[21] Monaghan, J.J.; Kos, A.; "Solitary waves on a cretan beach", J. Waterway, Port, Coastal and Ocean Engineering, Vol.125, 1999, p.p.145-154

[22] Loa, Y.M.; Shao, S.; "Simulation of near-shore solitary wave mechanics by an incompressible SPH method", Applied Ocean Research, Vol.24, 2002, p.p.275-286,

[23] Dalrymple, R.A.; Rogers, B.D.; "Numerical modeling of water waves with the SPH method", Coastal Engineering, Vol. 53, 2005

[24] Liggett. JA. Fluid Mechanics. McGraw-Hill: New York, 1994.

[25] Liu, G. R.; Liu, M. B.; "Smoothed Particle Hydrodynamics -A Meshfree Particle Method", World Scientific, 2003

[26] Monaghan, J.J.; "Smoothed particle hydrodynamics", Reports on Progress in Physics, 2005, p.p. 1703-1759,

[27] Monaghan, J.J.; "Smoothed particle hydrodynamics", Annual Review of Astronomy and Astrophysics, Vol. 30, 1992, p.p. 543-574

[28] Monaghan, J.J.; Lattanzio, J.C.; "A refned method for astrophysical problems”,Astron. Astrophys, 1985, p.p. 135-143

[29] Batchelor, G.; "An introduction to fluid dynamics", Cambridge University Press, 1967.

[30] Rogers, B.D.; Dalrymple, R.A.; "SPH modeling of breaking waves", Proc. 29th Intl. Conference on Coastal Engineering, 2004, p.p. 415- 427

[31] Monaghan J.J.,"On the problem of penetration in particle methods”, J. Comput. Phys., Vol., 82, 1989, p.p. 1-15

[32] Verlet, L.; "Computer experiments on classical fluids", I. Thermodynamical Properties of Lennard-Jones Molecules. Phys., p.p. 98-103,1967.

[33] Narayanaswamy, M.S.; Crespo, A.J.C.; Gómez, M.; Dalrymple, R.A.;“ SPHysics-Funwave hybrid model for coastal wave propagation”, Journal of Hydraulic Research, 2010.

[34] Monaghan, JJ. "Simulating free surface flows with SPH", Journal of Computational Physics, 1994, p.p. 399-406

[35] Colagrossi, A.; Landrini, M.; "Numerical simulation of interfacial flows by smoothed particle hydrodynamics", J. Comput. Phys, 2003,p.p. 448-75

[36] Dilts, G.A.; "Moving least squares hydrodynamics: consistency and stability”, Int. J. Numer. Methods, 44,1999

[37] Panizzo, A.; Dalrymple, R.A.; "SPH modeling of underwater landslide generated waves", Proc. 29th, International Conference on Coastal Engineering, 2004, p.p. 1147-1159

[38] Goring, D.G.; "Tsunamis the propagation of long waves onto a shelf”, W. M. Keck Laboratory of Hydraulics and Water Resources, California Institute of Technology, 1978

[39] Sangita, M.; "Computation of Solitary Waves during Propagation and Run-up on a Slope”, J. Ocean Engineering, Vol.26, 1999 